\title{
Characterization of Mechanical Properties of Aluminum Processed by Repetitive Corrugation and Straightening Process using Taguchi Analysis
}

\author{
H. S. SIDDESHA ${ }^{1,3}$ and M. SHANTHARAJA ${ }^{2,4}$ \\ 1.-Department of Mechanical Engineering, ACS College of Engineering, Bangalore 560074 , \\ India. 2.-Department of Mechanical Engineering, Bangalore University, UVCE, K.R. Circle, \\ Bangalore 560001, India. 3.—e-mail: skphss@gmail.com. 4.—e-mail: shantharajam@gmail.com
}

\begin{abstract}
The severe plastic deformation process is capable of developing the submicron grain structures in metallic alloys and to improve the mechanical properties. Repetitive corrugation and straightening (RCS) processes are widely used in industries to compensate the high-strength metal plates components used in automobiles. In this work, an attempt has been made to study the influence of RCS parameters like strain rate, number of passes, and plate thickness to produce grain refinement in metallic alloys. Experiments were based on the Taguchi method and the analysis of variance (ANOVA) technique was an effective tool to predict the degree of importance of the RCS parameters on grain size, microhardness, and tensile strength of RCS specimens. The results indicated that the number of passes has a major influence on the fine-grain refinement, followed by $\mathrm{Al}$ plate thickness and strain rate.
\end{abstract}

\section{INTRODUCTION}

The process of severe plastic deformation (SPD) is gaining great interest in material science because it is useful to refine microstructures to the submicrometer or nanometer levels. ${ }^{1}$ In Al-based alloys, it is generally difficult to reduce the grain size below $10 \mu \mathrm{m}$ through the conventional recrystallization process following thermomechanical treatments. This difficulty arises from the inherent nature of $\mathrm{Al}$ alloys that the stacking fault energy is relatively large so that it is easy for the recovery of dislocation to occur. $^{2}$ One of these advantages is a capability of producing large samples that are free from any residual porosity and readily amenable to mechanical testing and forming operations. ${ }^{3}$ Among the various SPD techniques proposed for processing bulk materials, very few methods like accumulative roll bonding (ARB), ${ }^{4,5}$ constrained groove pressing (CGP),, 7 and repetitive corrugation and straightening (RCS) $)^{8,9}$ are capable of processing sheet materials. The RCS process was invented recently, and it is a promising method for producing fine-grain-sheet material for structural applications. In the RCS process, a work piece is repetitively bent and straightened without significantly changing the cross-section geometry of the work piece, during which large plastic strains are imparted into the materials, leading to the refinement of microstructure. Although many researchers worked on RCS, ${ }^{10}$ thorough study is needed on the process parameters such as strain rate, number of passes, and thickness of the metal plate. They are influenced by different microstructural evolution and mechanical properties of RSC specimens.

In the current study, the morphological and mechanical behaviors were predicted through a statistical analysis of the measured grain size, microhardness, tensile strength at different conditions, and the effects of strain rate, number of passes, and plate thickness on RCS were found by using Taguchi $\mathrm{L}_{27}$ orthogonal array. The analysis of variance was employed to find the percentage of influence of various factors and its interaction on the physical behavior of RCS specimens.

\section{TAGUCHI METHOD}

The Taguchi method is an efficient tool that enables a performance upgrade of the product, process, and design with significant prediction of cost and time. It is a systematic approach for 
enabling the design optimization, thereby ensuring both quality and performance by means of Taguchi's parameter design concept. The system performance could be optimized by means of systematic setting of design parameters and reducing the fluctuations. This method employs a special design of orthogonal arrays to study all process parameters with a small number of experiments. ${ }^{11}$

\section{EXPERIMENTAL STUDIES}

In order to achieve the RCS on an $\mathrm{Al}$ test specimen, corrugated and flat dies are used in this research work. These dies are designed using an analytical method on the basis of loading parameters and test specimen specifications. A CATIA V5 tool was used for modeling of the dies according to design specifications. Technical specifications of the die are as follows: The cross-sectional area of corrugated die is $250 \times 250 \mathrm{~mm}^{2}$; the radius of the corrugated groves is $20 \mathrm{~mm}$; the depth of the groove is $5 \mathrm{~mm}$; the cross-sectional area of the flat die is $250 \times 250 \mathrm{~mm}^{2}$; the material to be forged is aluminum with maximum yield strength $145 \mathrm{MPa}$; the thicknesses of the test specimens to be forged are $3 \mathrm{~mm}, 4 \mathrm{~mm}$, and $5 \mathrm{~mm}$; the cross sectional area of the test specimens to be forged is $20 \times 100 \mathrm{~mm}^{2}$; die material to be used is mild steel; and the overall tolerance of the geometry is $\pm 1 \mathrm{~mm}$. The components of the dies are designed on the basis of loading conditions and test specimen specifications. The key components of the dies are one pair of corrugated die, one pair of flat die, one pair of backup plates to absorb excess loads, eight Allen screws, and one pair of bevel pins for proper alignment. Final assembly is made by combining male and female dies along with the backup plates. The pressing is performed in a $250 \mathrm{~T}$ oil hydraulic press at pressing speeds of 1 $\mathrm{mm} / \mathrm{s}, 1.5 \mathrm{~mm} / \mathrm{s}$, and $2 \mathrm{~mm} / \mathrm{s}$. In an RCS process, plate material is subjected to repetitive shear deformation under plane strain conditions by pressing the sheet alternately between asymmetric grooved dies and flat dies. The sheets are subjected to a total number of five passes of RCS, and further processing could not be continued beyond due to cracking of the plate. The specimens were prepared for microstructure, hardness, and tensile specimen.

Polishing of the test specimens was conducted with different grade silicon carbide papers using an automatic polishing machine on one side of the mounted Al specimens. The polishing procedure starts from polishing with paper grades of 80,100 , $200,400,600,800$, and 1000 to obtain a fine surface finish. To obtain mirror finish on the polished surface, diamond paste with grades of 0 to 0.5 and 2 were used. The Keller's reagent was used as the etchant and the chemical composition is $2 \mathrm{~mL}$ hydrofluoric acid (HF), $3 \mathrm{~mL}$ hydrochloric acid $(\mathrm{HCl})$, and $5 \mathrm{~mL}$ nitric acid $\left(\mathrm{HNO}_{3}\right)$. After surface preparation, microstructure analysis was carried out on all the specimens using optical microscope.
Magnification of 500 times was used for the analysis, and the grain size was calculated in accordance with ASTM-E112. The Vickers hardness (HV) of the test specimens was calculated using a Micromet5101 device, with a load of $200 \mathrm{~g}$ and loading period of $20 \mathrm{~s}$. Tensile tests were performed at room temperature with universal testing machine at crosshead speed of $0.5 \mathrm{~mm} / \mathrm{min}$. The size of gauge part of the tensile specimen was $5 \mathrm{~mm}$ width and $40 \mathrm{~mm}$ length. The tensile test specimens were prepared as per dimensions using milling machine.

\section{Design Factors}

A standard Taguchi experimental plan with notation $\mathrm{L}_{27}\left(3^{3}\right)$ was chosen as shown in Table II. In this method, the experimental results are transformed into signal to noise $(\mathrm{S} / \mathrm{N})$ ratio. With $\mathrm{S} / \mathrm{N}$ ratio and ANOVA analysis, the optimal combination of the process parameters can be predicted. The experiments were carried out for analyzing the influence of testing parameters on microstructure and microhardness of RCS specimens. The code and levels of control parameters are shown in Table I. This table shows that the experimental plan had three levels. On conducting the experiments as per orthogonal array, the grain sizes, tensile strength, and hardness results for various combinations of parameters were obtained and shown in Table III. Based on ANOVA, the optimal combinations of the process parameters are predicted. This analysis is carried out for $99 \%$ confidence level (significance level $1 \%$ ).

\section{RESULT AND DISCUSSION}

\section{Microstructure}

Figure 1 shows the optical images of the specimen's as cast specimen microstructure (Fig. 1a) and with RCS after one pass for different strain rate, i.e., $1 \mathrm{~mm} / \mathrm{min}, 1.5 \mathrm{~mm} / \mathrm{min}$, and $2 \mathrm{~mm} / \mathrm{min}$ for 3-mm aluminum plate. As-cast specimen exhibits strong wire texture and measured average width of the texture is about $65 \mu \mathrm{m}$. It can be seen from Fig. 1b-d despite different strain rate the average microstructure texture is about $45 \mu \mathrm{m}$. The influence of strain rate not seen in the entire specimen for modification of grain boundaries. It can be seen from Fig. $2 \mathrm{a}$ that the microstructure of the specimens without RCS exhibits strong wire texture and

Table I. Control Factors and Levels

\begin{tabular}{|c|c|c|c|}
\hline \multirow[b]{2}{*}{ Factors } & \multicolumn{3}{|c|}{ Levels } \\
\hline & 1 & 2 & 3 \\
\hline Strain rate $(\mathrm{mm} / \mathrm{min})$ & 1.00 & 1.50 & 2.00 \\
\hline Number of passes & 1 & 3 & \\
\hline Plate thickness (mm) & 3.00 & 4.00 & 5.00 \\
\hline
\end{tabular}


Table II. $\mathbf{L}_{27}$ Orthogonal Array and Factor Assignment

\begin{tabular}{|c|c|c|c|c|c|c|c|c|c|c|c|c|c|}
\hline \multirow[b]{2}{*}{ Expt. No. } & \multicolumn{6}{|c|}{$\begin{array}{c}\text { Column Number and Factor } \\
\text { Assignment }\end{array}$} & & \multicolumn{6}{|c|}{$\begin{array}{c}\text { Column Number and Factor } \\
\text { Assignment }\end{array}$} \\
\hline & $\mathbf{1}$ & $\begin{array}{l}\mathbf{2} \\
\mathbf{B}\end{array}$ & $\begin{array}{c}3 \\
\mathbf{A B}\end{array}$ & $\begin{array}{l}\mathbf{5} \\
\mathbf{C}\end{array}$ & $\begin{array}{c}6 \\
\mathbf{A C}\end{array}$ & $\stackrel{8}{\mathbf{B C}}$ & Expt. No. & $\mathbf{1}$ & $\begin{array}{l}\mathbf{2} \\
\mathbf{B}\end{array}$ & $\begin{array}{c}3 \\
\mathbf{A B}\end{array}$ & $\begin{array}{l}\mathbf{5} \\
\mathbf{C}\end{array}$ & $\stackrel{6}{\mathbf{A C}}$ & $\stackrel{8}{8}$ \\
\hline 1 & 1 & 1 & 1 & 1 & 1 & 1 & 15 & 2 & 2 & 3 & 3 & 1 & 1 \\
\hline 2 & 1 & 1 & 1 & 2 & 2 & 2 & 16 & 2 & 3 & 1 & 1 & 2 & 3 \\
\hline 3 & 1 & 1 & 1 & 3 & 3 & 3 & 17 & 2 & 3 & 1 & 2 & 3 & 1 \\
\hline 4 & 1 & 2 & 2 & 1 & 1 & 2 & 18 & 2 & 3 & 1 & 3 & 1 & 2 \\
\hline 5 & 1 & 2 & 2 & 2 & 2 & 3 & 19 & 3 & 1 & 3 & 1 & 3 & 1 \\
\hline 6 & 1 & 2 & 2 & 3 & 3 & 1 & 20 & 3 & 1 & 3 & 2 & 1 & 2 \\
\hline 7 & 1 & 3 & 3 & 1 & 1 & 3 & 21 & 3 & 1 & 3 & 3 & 2 & 3 \\
\hline 8 & 1 & 3 & 3 & 2 & 2 & 1 & 22 & 3 & 2 & 1 & 1 & 3 & 2 \\
\hline 9 & 1 & 3 & 3 & 3 & 3 & 2 & 23 & 3 & 2 & 1 & 2 & 1 & 3 \\
\hline 10 & 2 & 1 & 2 & 1 & 2 & 1 & 24 & 3 & 2 & 1 & 3 & 2 & 1 \\
\hline 11 & 2 & 1 & 2 & 2 & 3 & 2 & 25 & 3 & 3 & 2 & 1 & 3 & 3 \\
\hline 12 & 2 & 1 & 2 & 3 & 1 & 3 & 26 & 3 & 3 & 2 & 2 & 1 & 1 \\
\hline 13 & 2 & 2 & 3 & 1 & 2 & 2 & 27 & 3 & 3 & 2 & 3 & 2 & 2 \\
\hline 14 & 2 & 3 & 2 & 2 & 3 & 3 & & & & & & & \\
\hline
\end{tabular}

Table III. The Experimental Layout and Results of the Microhardness, Tensile Strength, and Grain Size Testing Process

\begin{tabular}{|c|c|c|c|c|c|c|}
\hline \multirow[b]{2}{*}{ Expt. No. (mm) } & \multicolumn{3}{|c|}{ Experimental Condition Matrix } & \multirow[b]{2}{*}{$\begin{array}{c}\text { Microhardness } \\
\text { Hv }\end{array}$} & \multirow[b]{2}{*}{$\begin{array}{c}\text { Tensile } \\
\text { Strength MPa }\end{array}$} & \multirow[b]{2}{*}{$\begin{array}{l}\text { Grain Size } \\
\text { in Microns }\end{array}$} \\
\hline & $\begin{array}{l}\text { Strain Rate } \\
(\mathrm{mm} / \mathrm{min})\end{array}$ & $\begin{array}{l}\text { No. of } \\
\text { Passes }\end{array}$ & $\begin{array}{c}\text { Thickness, } \\
\text { in }\end{array}$ & & & \\
\hline 01 & 1 & 1 & 3 & 44.48 & 94.82 & 7.7 \\
\hline 02 & 1 & 1 & 4 & 43.27 & 97.31 & 7.9 \\
\hline 03 & 1 & 1 & 5 & 43.02 & 76.38 & 8.0 \\
\hline 04 & 1 & 3 & 3 & 46.17 & 105.96 & 6.5 \\
\hline 05 & 1 & 3 & 4 & 45.50 & 109.81 & 6.4 \\
\hline 06 & 1 & 3 & 5 & 45.70 & 89.29 & 5.6 \\
\hline 07 & 1 & 5 & 3 & 49.20 & 113.00 & 3.8 \\
\hline 08 & 1 & 5 & 4 & 48.65 & 120.00 & 3.1 \\
\hline 09 & 1 & 5 & 5 & 47.98 & 96.00 & 4.0 \\
\hline 10 & 1.5 & 1 & 3 & 46.01 & 97.70 & 8.0 \\
\hline 11 & 1.5 & 1 & 4 & 44.38 & 96.92 & 7.2 \\
\hline 12 & 1.5 & 1 & 5 & 42.79 & 79.07 & 6.7 \\
\hline 13 & 1.5 & 3 & 3 & 47.62 & 104.95 & 6.7 \\
\hline 14 & 1.5 & 3 & 4 & 46.19 & 109.58 & 5.8 \\
\hline 15 & 1.5 & 3 & 5 & 45.45 & 91.10 & 5.0 \\
\hline 16 & 1.5 & 5 & 3 & 52.78 & 114.7 & 4.2 \\
\hline 17 & 1.5 & 5 & 4 & 52.73 & 119.01 & 3.5 \\
\hline 18 & 1.5 & 5 & 5 & 50.08 & 96.25 & 4.7 \\
\hline 19 & 2 & 1 & 3 & 46.33 & 95.92 & 8.0 \\
\hline 20 & 2 & 1 & 4 & 44.82 & 96.09 & 7.6 \\
\hline 21 & 2 & 1 & 5 & 42.33 & 78.69 & 6.4 \\
\hline 22 & 2 & 3 & 3 & 47.91 & 104.51 & 6.3 \\
\hline 23 & 2 & 3 & 4 & 46.02 & 112.10 & 5.6 \\
\hline 24 & 2 & 3 & 5 & 44.18 & 88.44 & 5.1 \\
\hline 25 & 2 & 5 & 3 & 52.13 & 115.13 & 4.2 \\
\hline 26 & 2 & 5 & 4 & 52.23 & 121.94 & 3.8 \\
\hline 27 & 2 & 5 & 5 & 49.63 & 97.10 & 4.6 \\
\hline
\end{tabular}

the measured average width of the texture is about $70 \mu \mathrm{m}$. Figure $2 \mathrm{~b}-\mathrm{d}$ shows great influence the number of passes on modification of grain boundaries.
The grain boundaries drastically change from $70 \mu \mathrm{m}$ to $30 \mu \mathrm{m}$ for three passes. The $\alpha$ phase parallels the second phase, and both of them are 

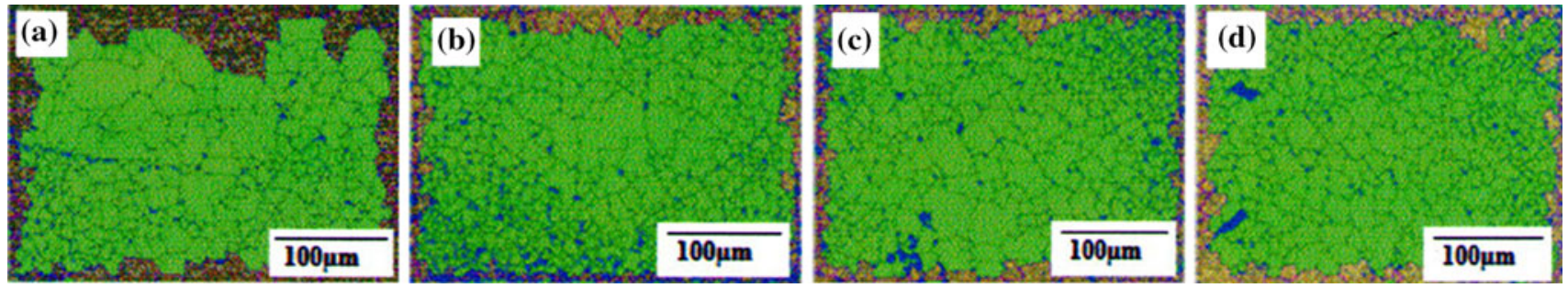

Fig. 1. Optical micrographs of (a) as cast, (b) strain rate of $1 \mathrm{~mm} / \mathrm{min}$, (c) $1.5 \mathrm{~mm} / \mathrm{min}$, and (d) $2 \mathrm{~mm} / \mathrm{min}$ for 3-mm-thick plate for one pass.
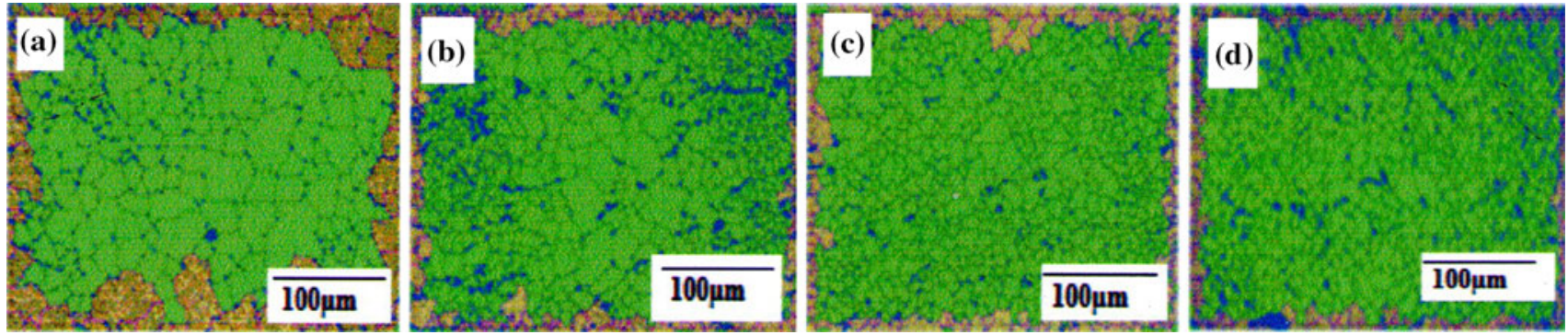

Fig. 2. Optical micrographs of (a) as cast, (b) 1 pass, (c) 3 passes, and (d) 5 passes for 4-mm-thick plate at strain rate of $1.5 \mathrm{~mm} / \mathrm{s}$.
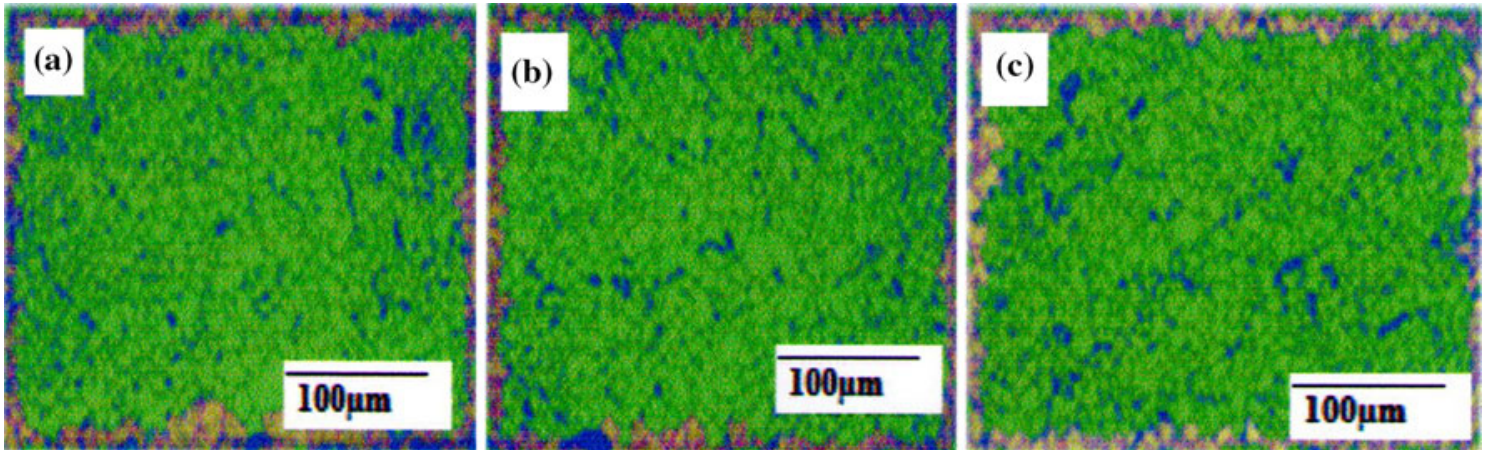

Fig. 3. Optical micrographs of plate thickness of (a) $3 \mathrm{~mm}$, (b) $4 \mathrm{~mm}$, and (c) $5 \mathrm{~mm}$ at strain rate of $\mathrm{mm} / \mathrm{min}$ and two passes.

elongated along the rolling direction. After one pass of RCS, the grain structure is refined and the microstructure of the specimen evolves into a structure with a considerable fraction of low-angle boundaries, as seen in Fig. 2b. Most of the lowangle grain boundaries still align along the extrusion direction, but some low-angle boundaries deviate from the extrusion direction. Therefore, it can be seen that in some areas, $\alpha$ phase intersects the second phase and the grain boundaries are no longer straight, but more curved than the boundaries without RCS. After three passes of RCS, the spacing of the boundaries is about $30 \mu \mathrm{m}$ and some grains occur in some areas, although the proportion of low-angle grains is large. After five passes of RCS, the grain size is further refined and the spacing of the boundaries is about $27 \mu \mathrm{m}$, as shown in Fig. 2d. It can be seen from Fig. 3 that the microstructure of the specimens shows the influence of plate thickness on grain refinement.
The improvement of the mechanical properties is attributed to the difference in microstructures between as-received and RCS aluminum specimens. Grain size decreased and grain was refined during the progress of RCS. Grain refinement can affect mechanical properties of polycrystalline materials. ${ }^{6}$ The classical effect of grain size on hardness can be explained by the Hall-Petch model ${ }^{7}$ :

$$
H=H_{0}+k d^{-0.5}
$$

where $H_{0}$ is the hardness constant, $k$ the constant, and $d$ is the diameter of the grain. The Hall-Petch effect in grain refinement materials is attributed to the grain boundaries acting as efficient obstacles to dislocations. Consequently, a dislocation pile-up can be formed against a grain boundary inside a grain.

\section{ANOVA Results}

The ANOVA has been performed to predict the statistical significance of the process parameters. It 
Table IV. ANOVA for Multiple Performance Characteristics

\begin{tabular}{|c|c|c|c|c|c|c|}
\hline Source & $\begin{array}{c}\text { Degrees } \\
\text { of Freedom }\end{array}$ & $\begin{array}{c}\text { Sum of } \\
\text { Squares (SS) }\end{array}$ & $\begin{array}{l}\text { Mean Squares } \\
\text { Variance (MS) }\end{array}$ & $\boldsymbol{F}_{\text {cal }}$ & $F_{\text {tab }}$ & $\% P$ \\
\hline $\mathrm{A}$ & 2 & 0.007 & 0.004 & 0.999 & 8.65 & 0.9 \\
\hline $\mathrm{B}$ & 2 & 0.584 & 0.292 & 79.693 & 8.65 & 77.8 \\
\hline $\mathrm{C}$ & 2 & 0.091 & 0.046 & 12.439 & 8.65 & 12.1 \\
\hline$A \times B$ & 4 & 0.001 & 0.000 & 0.096 & 7.01 & 0.2 \\
\hline$A \times C$ & 4 & 0.000 & 0.000 & 0.029 & 7.01 & 0.0 \\
\hline $\mathrm{B} \times \mathrm{C}$ & 4 & 0.037 & 0.009 & 2.520 & 7.01 & 4.9 \\
\hline Error & 8 & 0.029 & 0.004 & - & - & - \\
\hline Total & 26 & 0.750 & - & & & - \\
\hline
\end{tabular}

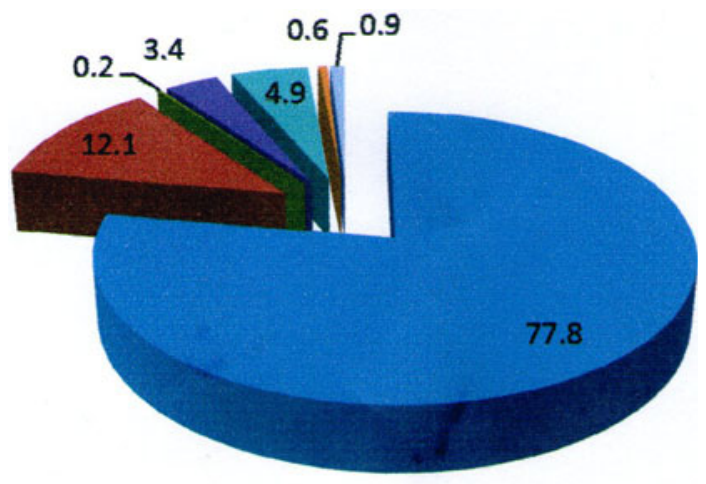

- $\mathrm{A}=\mathrm{B}=\mathrm{C}=\mathrm{AXB}=\mathrm{AXC}=\mathrm{BXC}$ werror

Fig. 4. Contribution in $\%$ most influencing parameters for physical properties of RCS.

helps to determine the effect of individual input parameter on output parameters. The results of ANOVA presented for RCS in Table IV indicate the percentage contribution $(P)$ of each factor on the total variation with their degree of influence on the result. The table shows the influence of strain rate $(A=0.9 \%)$, number of passes $(B=77.8 \%)$, and thickness of the plate $(C=12.1 \%)$. The pooled error is $0.009 \%$.

Based on the results presented in Table IV, the number of passes is found to be the most influencing process parameter, followed by plate thickness and strain rate (Fig. 4). The ranking of process parameters generated by the conduct of Taguchi method is shown in Table IV.

\section{CONCLUSION}

- It is demonstrated that the extrusion strain rate of RCS for aluminum alloy must be higher than the eutectoid reaction temperature of the alloy. The alloy has a more homogeneous fine-grained structure than the as-received one, and some equiaxed grains occur in some areas. The fraction volume of the second phase increases after one pass, while it does not increase during the subsequent pass.

- From the Taguchi gray relational analysis, it is concluded that, at 99\% confidence level, the number of passes has the highest contribution toward the response values obtained, and the strain rate occupies the second highest contribution rate.

- The probability of contribution for number of pass and strain rate is $77.8 \%$ and $12.1 \%$.

- The remaining parameters such as specimen thickness and combining effects of strain rate, number of passes, and thickness is less significant toward the response values.

\section{OPEN ACCESS}

This article is distributed under the terms of the Creative Commons Attribution License which permits any use, distribution, and reproduction in any medium, provided the original author(s) and the source are credited.

\section{REFERENCES}

1. Z. Horita, K. Oh-ishi, and K. Kaneko, Sci. Technol. Adv. Mater. 7, 649 (2006).

2. Z. Horita, T. Fujinami, M. Nemoto, and T.G. Langdon, J. Mater. Proc. Technol. 117, 288 (2001).

3. O.N. Senkov, F.H. Froes, V.V. Stolyarov, R.Z. Valiev, and J. Liu, Scripta Mater. 38, 1511 (1998).

4. Y. Saito, N. Tsuji, H. Utsunomiya, T. Sakai, and R.G. Hong, Scripta Mater. 39, 1221 (1998).

5. D.H. Shin, J.J. Park, Y.S. Kim, and K.T. Park, Mater. Sci. Eng. A 328A, 98 (2002).

6. A. Krishnaiah, U. Chakkingal, and P. Venugopal, Scripta Mater. 52, 1229 (2005).

7. A. Krishnaiah, U. Chakkingal, and P. Venugopal, Mater. Sci. Eng. A 411A, 337 (2005).

8. Y.T. Zhu, H. Jiang, J.Y. Huang, and T.C. Lowe, Metall. Mater. Trans. A 32A, 1559 (2001).

9. J.Y. Huang, Y.T. Zhu, H. Jiang, and T.C. Lowe, Acta Mater. 49, 1497 (2001).

10. V.Rajinikanth, G. Arora, N. Narasaiah, and K. Venkateswarlu, Mater. Lett. 62, 301 (2008).

11. M. Senthil Kumar and S. Natarajan, Int. J. Eng. Sci. Technol. 3, 3336 (2011). 